Full length article

\title{
Biopolymer production and end of life comparisons using life cycle assessment
}

\author{
Troy A. Hottle ${ }^{\mathrm{a}, *}$, Melissa M. Bilec ${ }^{\mathrm{b}}$, Amy E. Landis $^{\mathrm{c}}$ \\ ${ }^{a}$ Arizona State University, School of Sustainable Engineering and the Built Environment, College Avenue Commons, 660 South College Avenue, Tempe, AZ, \\ 85287-6004, USA \\ b University of Pittsburgh, Civil and Environmental Engineering, 153 Benedum Hall, 3700 O'Hara Street, Pittsburgh, PA, 15261-3949, USA \\ c Clemson University, Glenn Department of Civil Engineering, Lowry Hall, 306 S. Palmetto Blvd., Clemson, SC, 29634, USA
}

\section{A R T I C L E I N F O}

\section{Article history:}

Received 3 January 2017

Received in revised form 8 March 2017

Accepted 9 March 2017

Available online 21 March 2017

\section{Keywords:}

Bioplastic

Waste

LCA

Compost

Recycle

Polylactic acid

\begin{abstract}
A B S T R A C T
This paper presents an attributional life cycle assessment of biopolymers and traditional plastics using real world disposal methods based on collected data and existing inventories. The focus of this LCA is to investigate actual disposal methods for the end of life phase of biopolymers and traditional fossil-based plastics relative to their corresponding production impacts. This paper connects commonly available methods of disposal for traditional fossil-based plastics and the compostability of polylactic acid and thermoplastic starch to compare these materials not just based on production impacts but also on various scenarios for recycling, composting, and landfilling. Additionally, three traditional resins were evaluated (PET, HDPE, and LDPE) using fossil and bio-based production pathways to assess the performance of biobased products in the recycling stream. The results demonstrate real environmental tradeoffs associated with agricultural production of plastics and the consequential changes resulting from shifting from recyclable to compostable products. The potential for methane production in landfills is a significant factor for global warming impacts associated with biopolymers while recycling provides major benefits in the global warming and fossil fuel depletion categories. A sensitivity analysis was conducted to investigate the relative importance of locale-specific factors such as travel distances and sorting technologies to the end of life treatment methods of recycling, composting, and landfilling. The results show that composting has some advantages, especially when compared to impacts associated with landfilling, but that recycling provides the greatest benefits at end of life.
\end{abstract}

(c) 2017 Elsevier B.V. All rights reserved.

\section{Introduction}

Biopolymers are a growing segment of the plastics market primarily in packaging and disposable products (Shen et al., 2010). Biopolymers are plastics that can be produced, at least in part, from renewable materials such as corn and sugar cane. Some biopolymers, like Bio-PET, are blends of conventional and renewable feedstocks (Shen et al., 2010; Hartmann, 1998; Shen et al., 2009). These bio-based plastics have gained interest as an alternative to fossil based plastics because of the potential to shift to more environmentally friendly production and waste handling (Meeks et al., 2015). Some commercially available biopolymers are compostable, though many require conditions for degradation only

\footnotetext{
* Corresponding author.

E-mail address: troy.hottle@asu.edu (T.A. Hottle).
}

attainable in commercial-scale composting facilities (Meeks et al., 2015; Hottle et al., 2013; Yates and Barlow, 2013).

Traditional plastic production is a mature industry with materials produced using fossil resources such as petroleum and natural gas. The US Environmental Protection Agency (EPA) reported that in 2013, plastics contributed to $13 \%$, by weight, of the municipal solid waste (MSW) in the US totaling about 32.5 million tons of plastic waste generated annually (USEPA, 2015). Nine percent of plastics entering the waste stream were recovered for recycling, though recovery rate is not necessarily indicative of a final recycling rate. Of total plastics, about $91 \%$ are discarded to a landfill or are incinerated. While overall recovery of plastics for recycling was only $9 \%$, recovery of certain plastic containers is more significant. In 2013 polyethylene terephthalate (PET) soft drink bottles were recovered at a rate of $31 \%$ while high-density polyethylene (HDPE) milk and water bottles were estimated at about 28\% (USEPA, 2015). Despite the ability to increase recovery rates of fossil based plastic mate- 
rials, concerns over increased fossil resource use, greenhouse gas emissions, pollution, and human health impacts associated with plastics have driven an increasing interest in the use of biopolymers (Gironi and Piemonte, 2011; Ren, 2003; Gómez and Michel, 2013; Kijchavengkul and Auras, 2008; Álvarez-Chávez et al., 2012).

Bio-PET is the same polymer as PET aside from the fact that the ethylene glycol component is bio-based rather than fossil-based and they can be recycled together since they are chemically identical (Tabone et al., 2010; Morschbacker, 2009). A fully bio-based PET has been developed which includes both ethylene glycol and terephthalic acid components derived from renewable feedstocks but is not expected to be implemented into the market until 2020 (Plastics Technology Coca-Cola Debuts, 2017). Bio-PET is used in Coca-Cola's Plantbottle ${ }^{\mathrm{TM}}$ and is the most prevalent biopolymer in the market (European Bioplastics, 2014; Coca-Cola Coca-Cola GRI Report, 2012). Other biopolymers such as polylactic acid (PLA) and thermoplastic starch (TPS) are compostable (Song et al., 2009). PLA is the most prevalent compostable biopolymer on the market and although it is also technically recyclable, given the current infrastructure and material flow, recycling is not a widely available option for PLA (European Bioplastics, 2014; Song et al., 2009; Soroudi and Jakubowicz, 2013). Compostable biopolymers must conform to American Society of Testing and Materials (ASTM) standards; ASTM D6400-04 Standard Specification for Compostable Plastics and ASTM D6868-03 Standard Specification for Biodegradable Plastics Used as Coatings on Paper and Other Compostable Substrates (Song et al., 2009; ASTM, 2004; ASTM, 2003). Compostable biopolymers often have specific time and temperature requirements needed to achieve efficient degradation and these often necessitate processing at a commercial composting operation (Kijchavengkul and Auras, 2008; Álvarez-Chávez et al., 2012). However, some compostable biopolymer products are coming under increasing scrutiny because they are not fully degrading in commercial composting facilities, complicating the waste management for users and waste handlers of these products (Gómez and Michel, 2013; Cedar Grove Compostabilty Testing, 2014; Ghorpade et al., 2001; Mohee and Unmar, 2007).

Life cycle assessment (LCA) is a well-established method used to quantify the environmental impacts of products and processes. Previous LCAs and environmental assessments of biopolymers are largely limited to global warming potential and fossil fuel depletion impact categories which may favor biopolymers because of the inherent properties of plastics made from biogenic carbon, which is carbon that was recently captured from the atmosphere through the biological process of photosynthesis by plants, compared to fossil based plastics and may miss the potential environmental tradeoffs that can occur when shifting to agriculturally produced feedstocks. Additionally, few past LCAs of biopolymers address end of life (EOL) (Hottle et al., 2013; Miller et al., 2007; Landis et al., 2007).

EOL, the processes involved in handling and treating a material after it enters the waste stream, has been shown to be significant for traditional plastics (USEPA, 2015; Björklund and Finnveden, 2005; Hopewell et al., 2009). When waste scenarios are included in biopolymer LCAs, findings vary widely based on the chosen EOL scenarios (e.g. landfilling, recycling, incinerating, composting) which are not always based on realistically available disposal methods (Hottle et al., 2013; Yates and Barlow, 2013; Koller et al., 2013; Shen and Patel, 2008; Weiss et al., 2012). Of the twentyone LCAs reviewed in Hottle et al. (2013) only seven included EOL within the system boundaries. Of the seven studies which evaluated EOL, only one study included composting as an EOL scenario for compostable biopolymers. Only four studies evaluated landfilling scenarios while five included scenarios for incineration which is a less common disposal method for plastics garbage compared to landfilling (USEPA, 2015). Increasingly there have been calls to fur- ther investigate the EOL for biopolymers (Hottle et al., 2013; Yates and Barlow, 2013; Weiss et al., 2012; Rossi et al., 2014; Hermann et al., 2011). At the same time, there have been inventory improvements for the production of biopolymers and waste streams in the United States that can be used for refining LCAs (Kolstad et al., 2012; Hermann et al., 2011; Vink et al., 2010a; Pressley et al., 2015; Vink and Davies, 2015).

This life cycle assessment (LCA) seeks to explore the impacts associated with the production and disposal of biopolymers compared to fossil-based plastics; most literature on biopolymers has neglected EOL, which studies say could significantly impact the overall life-cycle impacts of biopolymers (Hottle et al., 2013; Hottle et al., 2015). The model presented herein explores the production of biopolymers and traditional fossil based plastics as well as EOL model scenarios including landfill, compost, and recycle. For each recyclable polymer (PET, Bio-PET, HDPE, Bio-HDPE, LDPE, and BioLDPE) landfill and recycling scenarios are used, while the remaining compostable polymers (PLA and TPS) are modeled using compost and landfill scenarios.

\section{Methods}

LCA is a well-established method used to quantify impacts that can be attributed to the life cycle of products to help identify tradeoffs between impacts and to avoid shifting burdens to other products or processes. The International Organization for Standardization (ISO) defines LCA and its applications in ISO-14040 (ISO Environmental management, 2006, ISO 14040) and ISO-14044 (ISO Environmental management, 2006, ISO 14044). The LCA framework as defined by ISO includes an iterative process of: 1) Goal and Scope Definition, 2) Inventory Analysis, 3) Impact Analysis, and 4) Interpretation (ISO Environmental management, 2006, ISO 14040). LCAs require large amounts of data to provide accurate inventories for all of the processes associated with the production, use, and EOL for a product. The data used in this study come from existing inventories, literature sources, and new inventory data collected specifically for this research. The methodological details are described below.

\subsection{Scope and system boundary}

Fig. 1 depicts the system boundaries for the LCA. This study conducted an attributional, cradle-to-grave LCA with a functional unit of $1 \mathrm{~kg}$ of polymer with allocations calculated on a mass basis. The LCA evaluated the materials, processes, and technologies available at the time the assessment was conducted in 2015. Eight polymers were evaluated in the study: PLA, TPS, PET, Bio-PET, HDPE, BioHDPE, LDPE, and Bio-LDPE. These polymers were selected because PLA, TPS, Bio-PE and Bio-PET represent the most common biopolymers globally with $11.4 \%, 11.3 \%, 12.3 \%$, and $37 \%$ market shares of biopolymers, respectively (European Bioplastics, 2014). PLA is made from corn grown in the US and produced at the NatureWorks facility in Blair, Nebraska. The Bio-PET is synthesized in part from ethylene glycol which, in this model, comes from sugar cane grown and distilled in Brazil while the terephthalic acid component remains a fossil input (Tabone et al., 2010; Brehmer and Sanders, 2009). Bio-HDPE and Bio-LDPE modeled the use of Brazilian sugar cane based ethylene. Both the ethylene glycol and ethylene processes included freighter shipment to the U.S. Transportation for the production of the other polymers were based on published inventories. TPS was modeled based on the global corn market and US-based production. The traditional fossil-based polymers, HDPE, LDPE, and PET, were modeled based on standard production technologies using inventories published by Franklin Associates (Franklin Associates Revised Final Report, 2011). Product formation (e.g. blown film extrusion, sheet extrusion, thermoforming, 


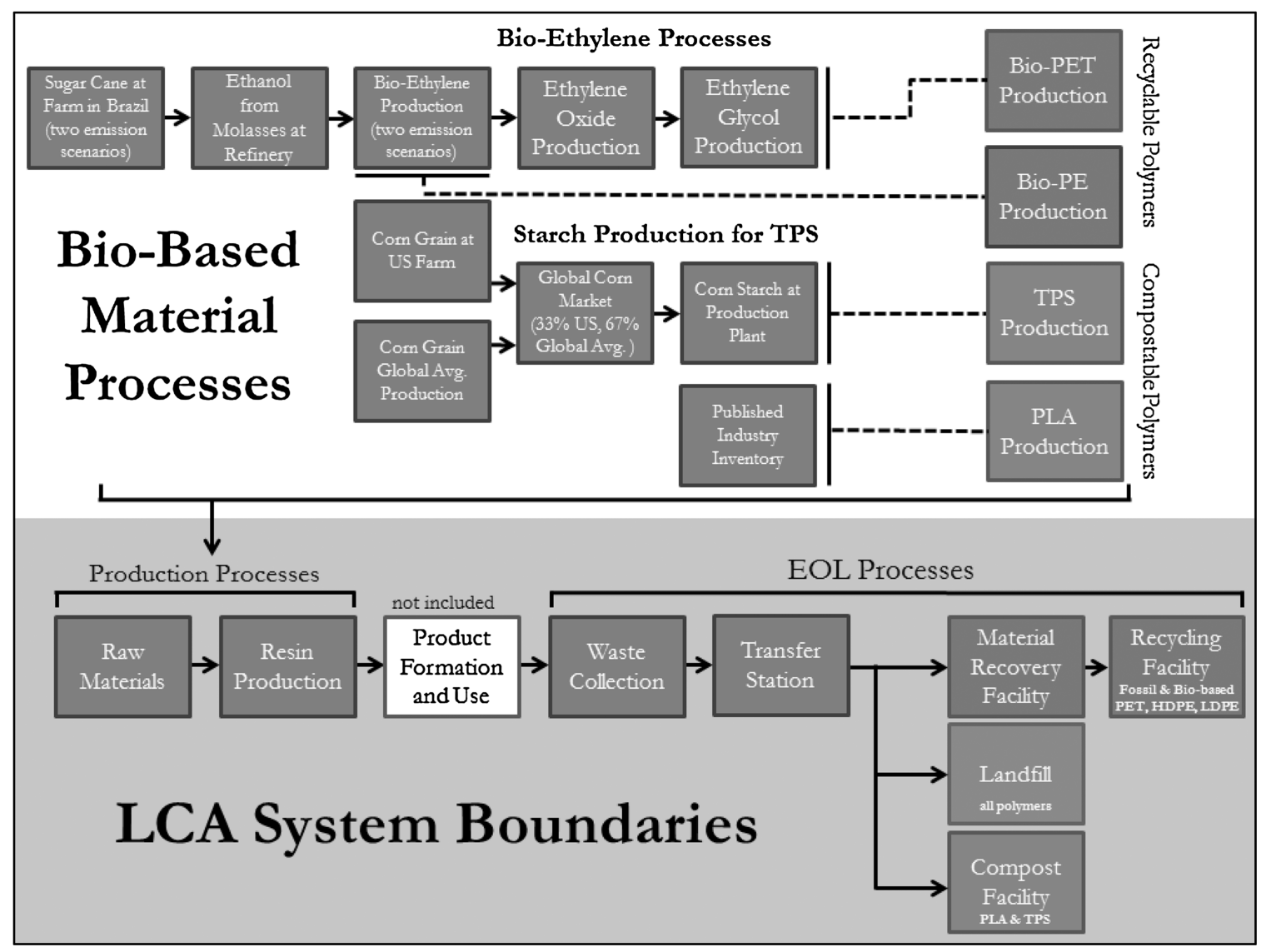

Fig. 1. Bio-based material processes and system boundaries for the LCA of eight polymers including production and EOL processes. Included in the assessments is transportation and energy inputs for all of the processes. The colors represent different EOL pathways with recyclable polymers and recycling processes in blue, compostable polymers and compost processes in green, and landfill in brown which is a model scenario for all polymers. Biogenic carbon is credited at the raw material processes and the benefits from recycling were allocated at EOL. The bio-ethylene and starch processes contribute to the raw materials used in the respective inventories. All other raw materials, including terephthalic acid for Bio-PET, are included in the 'Raw Materials' process which were developed using the inventories described in Table 1. PLA production was modeled using gross emissions data and not a process flow within the LCA model (Vink et al., 2010b). (For interpretation of the references to colour in this figure legend, the reader is referred to the web version of this article.)

and injection molding) and use of plastics were excluded from this LCA because there is such wide variability in formation technologies for each polymer as well as product shapes, sizes, lifetime, and functions (Shen et al., 2010; Shen et al., 2009).

In addition to the production of the polymer resins, this assessment included EOL processes starting with waste services common to all polymers which are waste collection and transfer station activities (shown in Fig. 1) and ended with three options currently available for EOL; recycle, compost, or landfill. Each polymer was evaluated using two EOL model scenarios; $100 \%$ landfill and one alternative EOL treatment at $100 \%$. Consumers (e.g. businesses and individuals) typically decide whether to dispose of waste via garbage cans or an alternative like compost or recycling bins with various assumptions underlying their decision making process (Meeks et al., 2015). All polymers were evaluated using a landfill EOL model scenario for the garbage pathway because landfilling is the predominant destination for plastics in the United States. Incineration, which is not included, is a less common pathway for garbage (with landfill accounting for $82 \%$ of garbage wastes) and has been a declining method of disposal for solid wastes (USEPA, 2015). The second EOL model scenario was based upon whether the material is recyclable or compostable. Linear correlations were used to interpolate for all intermediate ratios between landfilling and the alternative treatment method (either composting or recycling).
In the case of PLA which is technically recyclable but there is no large scale infrastructure to do so (Soroudi and Jakubowicz, 2013), composting was modeled. The exclusion of PLA recycling from the model was based on the discussions with the operators of the Sky Harbor Tipping Floor and Transfer Station and the Northwest Regional Materials Recovery Facility and Ecocenter operated by Waste Management Inc. (WM) in addition to conversations with NatureWorks LLC and EcoProducts which were conducted for a previously published study (Meeks et al., 2015). PLA is labeled with resin recycling code 7 , which denotes 'other' and is not typically sorted into its own stream for recycling. Additionally, NatureWorks, which is the largest North American producer of PLA, makes resins, not specific products for retail. According to NatureWorks and EcoProducts, product manufacturers often blend PLA with other raw materials to produce specific material characteristics based on the desired function which makes it difficult to recover and process for recycling. There is no indication that recycling via typical waste handling routes will become a practical option for PLA in North America in the near-term so it was excluded from the scope of this study which focuses on current, real-world disposal options available to consumers.

PLA has two landfill processes to model boundary scenarios due to the high level of uncertainty regarding landfill degradation. PLA is used in applications which include food serviceware, packaging, textiles, and durable goods. Semicrystalline PLA, which accounted for over 95\% of production volume in 2012 (Kolstad 
et al., 2012), is used in applications including rigid plastics, fibers, and films. The less common amorphous PLA is used in applications including fibers, films, and adhesives (Jamshidian et al., 2010; NatureWorks LLC Ingeo resin product guide, 2017). Amorphous PLA has been found to emit methane under landfill conditions. Semicrystalline PLA was shown by Kolstad et al. to not degrade at all under landfill conditions (Kolstad et al., 2012); however, Krause and Townsend found that it may degrade almost completely (Krause and Townsend, 2016). High and low emissions from PLA in landfills were modeled based on the amorphous and semicrystalline PLA degradation values determined by Kolstad et al. to create plausible boundaries (Kolstad et al., 2012). The high emissions landfill model falls near the middle of the range of degradation for semicrystalline PLA reported by Krause and Townsend (Krause and Townsend, 2016).

The different methods of transportation used to move waste materials between the EOL processes were included in the assessment. The EOL model scenarios, travel distances, and handling processes were based on services available in the Phoenix metropolitan region and were further evaluated using sensitivity analysis. The recycling process for plastics included baling at a material recovery facility (MRF), shipment via semi-truck to Long Beach, California, and transportation on an ocean freighter to Hong Kong (based on personal communication with employees of the Waste Management Northwest Regional Materials Recovery Facility and Ecocenter). In this study the benefits of offsetting virgin material production via recycling are allocated to the plas- tics during EOL. with the allocation methods described in the EOL Inventories section.

\subsection{Inventory}

Table 1 presents the various processes used to compile the life cycle inventory (LCI) data for the eight polymers; detailed $\mathrm{LCI}$ is presented in the Supporting Information (SI). The process used to model the transfer station is based on data collected during site visits to the WM Sky Harbor Tipping Floor and Transfer Station located in Tempe, Arizona from 11 July 2014 to 17 July 2014 and follow-up communications with WM employees. The inventory for one of the process scenarios used for each of the compostable polymers was developed with the Maricopa Organics Recovery Facility operated by Garick in Maricopa, Arizona through a series of site visits between January 2013 and June 2014. The remaining processes were created or customized using data available within existing databases and literature so the inventories are applicable to the scope and boundaries of the study. Some of these processes were developed in other countries, largely Switzerland. Where appropriate sub-processes were altered to better represent the US system boundary which is further documented in the Product Inventories and EOL Inventories sections that follow as well as Table S1. All of the biopolymers were credited for the use of biogenic carbon during raw material acquisition from agricultural processes and any $\mathrm{CO}_{2}$ released from biogenic carbon at EOL is net-zero and accounted for in the complete life-cycle. However, under some con-

Table 1

Sources of inventory data for the processes used in the LCA and the name of the processes within the database or literature. $\mathrm{RER}=\mathrm{E} u r o p e a n$ data, $\mathrm{CH}=\mathrm{Swiss}$ data, GLO $=$ global average data, Alloc Def $=$ default allocation methods. More details are presented in the SI.

\begin{tabular}{|c|c|c|}
\hline Process & Database or Source & Process Name \\
\hline PLA production & Vink et al. (2010a) & 2009 Ingeo PLA \\
\hline TPS production & $\begin{array}{l}\text { ecoinvent v2 (Frischknecht et al., } \\
\text { 2005)/ Hottle et al., (2013) }\end{array}$ & revised TPS production including: Modified starch, at plant/RER unit process \\
\hline PET production & $\begin{array}{l}\text { Franklin Associates Revised Final } \\
\text { Report (2011) }\end{array}$ & cradle-to-resin life cycle inventory results for PET resin \\
\hline HDPE production & $\begin{array}{l}\text { Franklin Associates Revised Final } \\
\text { Report (2011) }\end{array}$ & cradle-to-resin life cycle inventory results for HDPE resin \\
\hline LDPE production & $\begin{array}{l}\text { Franklin Associates Revised Final } \\
\text { Report (2011) }\end{array}$ & cradle-to-resin life cycle inventory results for LDPE resin \\
\hline Bio-ethylene production & $\begin{array}{l}\text { ecoinvent v2 (Frischknecht et al., } \\
\text { 2005)/Tabone et al., (2010) }\end{array}$ & Multiple process scenarios \\
\hline PLA landfilling & $\begin{array}{l}\text { ecoinvent v2 (Frischknecht et al., } \\
\text { 2005)/Kolstad et al. (2012) }\end{array}$ & $\begin{array}{l}\text { custom PLA landfilling including: Disposal, polyethylene, } 0.4 \% \text { water, to sanitary } \\
\text { landfill/CH unit process }\end{array}$ \\
\hline PLA composting & $\begin{array}{l}\text { average - ecoinvent v3 (Weidema } \\
\text { et al., 2013)/site visit, personal } \\
\text { communication, and Kruger et al. } \\
\text { (2009) }\end{array}$ & $\begin{array}{l}\text { custom PLA composting and Biowaste }[\mathrm{CH}] \text { treatment of, composting | Alloc Def unit } \\
\text { process }\end{array}$ \\
\hline TPS landfilling & $\begin{array}{l}\text { ecoinvent v2 (Frischknecht et al., } \\
\text { 2005) }\end{array}$ & Disposal, packaging cardboard, $19.6 \%$ water, to sanitary landfill/CH unit process \\
\hline TPS composting & $\begin{array}{l}\text { average - ecoinvent v3 (Weidema } \\
\text { et al., 2013)/site visit, personal } \\
\text { communication, Piemonte (2011) } \\
\text { and Hermann et al. (2011) }\end{array}$ & $\begin{array}{l}\text { custom TPS composting and Biowaste }[\mathrm{CH}] \text { treatment of, composting and custom TPS } \\
\text { composting | Alloc Def unit process }\end{array}$ \\
\hline PET landfilling & $\begin{array}{l}\text { ecoinvent v2 (Frischknecht et al., } \\
\text { 2005) }\end{array}$ & Disposal, polyethylene terephthalate, $0.2 \%$ water, to sanitary landfill/ $\mathrm{CH}$ unit process \\
\hline PET recycling & $\begin{array}{l}\text { Franklin Associates Revised Final } \\
\text { Report (2011) }\end{array}$ & revised process including: PET (waste treatment) [GLO] recycling of PET \\
\hline HDPE/LDPE landfilling & $\begin{array}{l}\text { ecoinvent v2 (Frischknecht et al., } \\
\text { 2005) }\end{array}$ & Disposal, polyethylene, $0.4 \%$ water, to sanitary landfill/CH unit process \\
\hline HDPE/LDPE recycling & $\begin{array}{l}\text { Franklin Associates Revised Final } \\
\text { Report (2011) }\end{array}$ & revised process including: $\mathrm{PE}$ (waste treatment) [GLO] recycling of PE \\
\hline MRF operations & Pressley et al. (2015) & multiple process scenarios based on polymer type \\
\hline transfer station operations & site visit, personal communication & custom process (described below and Table S1) \\
\hline waste collection & $\begin{array}{l}\text { ecoinvent v3 (Weidema et al., } \\
\text { 2013) }\end{array}$ & $\begin{array}{l}\text { Municipal waste collection service by } 21 \text { metric ton lorry [GLO] market for | Alloc Def, } \\
\text { unit process }\end{array}$ \\
\hline $\begin{array}{l}\text { local transportation \& } \\
\text { recyclables ground } \\
\text { shipping }\end{array}$ & USLCI v1.6 (NREL, 2012) & Transport, single unit truck, diesel powered/US \\
\hline $\begin{array}{l}\text { recyclables international } \\
\text { shipping }\end{array}$ & USLCI v1.6 (NREL, 2012) & Transport, ocean freighter, average fuel mix/US \\
\hline
\end{tabular}


ditions biopolymers do not degrade and the carbon was considered sequestered while in others situations biopolymers release $\mathrm{CH}_{4}$ which results in net-positive GHG emissions from biogenic sources. These processes are described in further detail.

\subsubsection{Production inventories}

The production of TPS was modeled using ecoinvent v2 (Frischknecht et al., 2005) process for modified starch, however adjustments were made to the process so that it included global corn production and US natural gas, as opposed to corn grown in Switzerland and natural gas in an Italian market which are the defaults in the ecoinvent database (Hottle et al., 2013). The substitutions better matched production in the US and are described in detail in Table S1.

The ethylene glycol derived from Brazilian grown sugar cane was used to synthesize Bio-PET (Fig. 1). This process includes the combustion of residual sugarcane bagasse to supply process energy. The production processes of bio-ethylene and bio-ethylene glycol were modeled using inventories adapted from Tabone et al. (2010) which details the structure of these process scenarios. The scenarios included both high and low rates of emissions for sugar cane production and two methodologies for modeling the production of ethylene, resulting in four distinct process scenarios. The Bio-PET inventories were created by subtracting ethylene glycol within the ecoinvent database from the Franklin Associates inventory for PET resin (Franklin Associates Revised Final Report, 2011) and replacing it with an equivalent amount of bio-based ethylene glycol for each of the four emissions scenarios. The results of these four process scenarios were averaged for the Bio-PET inventory and the differences between the scenarios as well as transportation were explored in the sensitivity analysis. Ocean transport was adjusted from Tabone's et al. (2010) 15,000 miles to 12,500 km (6740 nautical miles) representing transport from Santos, Brazil to Port of Houston, which equates to $0.0125 \mathrm{tkm} / \mathrm{kg}$ of material shipped.

Ethylene production, which is a sub-process of ethylene glycol production, was used to synthesize Bio-HDPE and Bio-LDPE. The Bio-LDPE inventories were created by subtracting the ethylene component from the Franklin Associates inventory for LDPE resin (Franklin Associates Revised Final Report, 2011) using the ecoinvent process for ethylene and replacing it with an equivalent amount of bio-ethylene production for each of the four process scenarios (Table S1). The Bio-HDPE inventories were created using the same method for each of the four process scenarios and transportation described above. The results of these four process scenarios were averaged for the Bio-HDPE and Bio-LDPE inventories and the differences between the scenarios as well as transportation were explored in the sensitivity analysis.

\subsubsection{EOL inventories}

The transfer station process was developed using data collected at the WM Sky Harbor Tipping Floor and Transfer Station. The transfer station is where local waste collection vehicles dump waste which is then consolidated into larger, regional transportation trucks bound for either the landfill, compost facility, or material recovery facility. The transfer station handles $2,000,000 \mathrm{~kg}(2200$ short tons) of waste material per day. The facility uses around $27,000 \mathrm{~L}$ ( $7200 \mathrm{gal}$ ) of water and $530 \mathrm{~L}$ ( $140 \mathrm{gal}$ ) of diesel fuel per day. The process was created using ecoinvent unit processes for $0.023 \mathrm{~kg}$ tap water and $0.0096 \mathrm{MJ}$ of equipment usage as well as USLCI data for $0.00027 \mathrm{~L}$ diesel used in the heavy equipment per kilogram of waste handled (details for unit processes are given in Table S1) (Frischknecht et al., 2005; Weidema et al., 2013). For PET, Bio-PET, HDPE, Bio-HDPE, LDPE, and Bio-LDPE MRF inventories were adapted from Pressley et al. (2015). The inventories include wire for baling, diesel, and electricity at varying rates depending upon the waste stream entering the MRF (e.g. single stream, pre- sorted, mixed waste, dual stream) and the type of polymer being sorted (Table S2) (Pressley et al., 2015). The impacts were calculated for each polymer and each MRF technology. The average impacts from all the MRF technologies were used for the baseline process, while the minimum and maximum impact from the different MRF technologies for each category were evaluated in the sensitivity analysis. LDPE was assumed to be film waste and was modeled as such in the MRF process scenarios.

For the transportation processes, the average distance to processing centers for the Phoenix, Arizona service area were mapped using Google Earth and used as a baseline for the model (Table S3). Minimum and maximum distances were evaluated in the sensitivity analysis (Table S9). Recycling incurred additional transport of the baled materials; $610 \mathrm{~km}$ ground transport (Phoenix, AZ to Long Beach, CA) and 11,686 km ocean freighter transport (Long Beach, CA to Hong Kong, China).

The recycling processes for PET and PE, developed by Pré Consultants, were modified to represent the Franklin Associates inventories for US produced plastics. This was accomplished by replacing the sub-process for the offset of virgin plastic production from the ecoinvent process for PET and HDPE production to the corresponding Franklin Associates inventories.

The fossil-based plastics are modeled based on what van der Harst et al. (2016) term a 'substitution-with-equal-quality' method, a one for one displacement of virgin materials via recycling. The model assumes that the bio-PET and bio-PE offset their fossilbased counterparts during recycling. This assumption is based on the fact that they are chemically identical and recycled together. Since this is the case, it is likely that upon reuse the plastics are offsetting traditional production routes. This is a 'substitutionwith-alternative-material' approach.

To address the uncertainty associated with recycling allocation highlighted by Geyer et al. (2016) and van der Harst et al. (2016), the sensitivity analysis includes the use of other methods of allocation described by van der Harst et al. (2016). These methods are 'substitution-with-correction-factor,' used for all of the recyclable polymers, and 'substitution-with-equal-quality' used for modeling the displacement of virgin biopolymers when biopolymers are recycled. A correction factor of 0.7 was used to assess a recycling system with $30 \%$ losses based on average values for plastics recovery (van der Harst et al., 2016).

TPS and PLA composting were modeled using two separate inventories for each material. One compost process scenario used a biowaste composting process from ecoinvent v2 with customized carbon dioxide and methane emissions for the degradation of PLA and TPS (Table S1). The mass of carbon dioxide and methane emissions for PLA and TPS were based on 60\% carbon content being released as air emissions with $95 \%$ of the carbon emissions resulting in $\mathrm{CO}_{2}$ and the remaining $5 \%$ resulting in $\mathrm{CH}_{4}$ (Hermann et al., 2011; Piemonte, 2011). These values are based on a completed composting process. For PLA this equated to $0.010 \mathrm{~kg}$ of biogenic methane and $1.05 \mathrm{~kg}$ of biogenic carbon dioxide per kilogram of PLA. For TPS this equated to $0.0089 \mathrm{~kg}$ of biogenic methane and $0.93 \mathrm{~kg}$ of biogenic carbon dioxide per kilogram of TPS, which has $88.8 \%$ of the carbon content of PLA (Hermann et al., 2011). The remaining $40 \%$ carbon from the biopolymers is expected to remain in the finished compost. The second process scenario used to model composting for PLA and TPS used the same $\mathrm{CO}_{2}$ and $\mathrm{CH}_{4}$ emissions described above but the underlying processes were based on data collected during site visits to the Maricopa Organics Recovery Facility operated by Garick in Maricopa, Arizona between January 2013 and June 2014. The facility handled $6000 \mathrm{~kg}$ (reported as 400,000 $\mathrm{lbs} /$ month) of organic waste per day, comprised of food and yard waste, which are composted in static piles that are watered regularly and turned weekly. The facility used around 68,000 L (reported as $18,000 \mathrm{gal} / \mathrm{day}$ ) of water and $150 \mathrm{~L}$ (reported as $40 \mathrm{gal} / \mathrm{day}$ ) of 


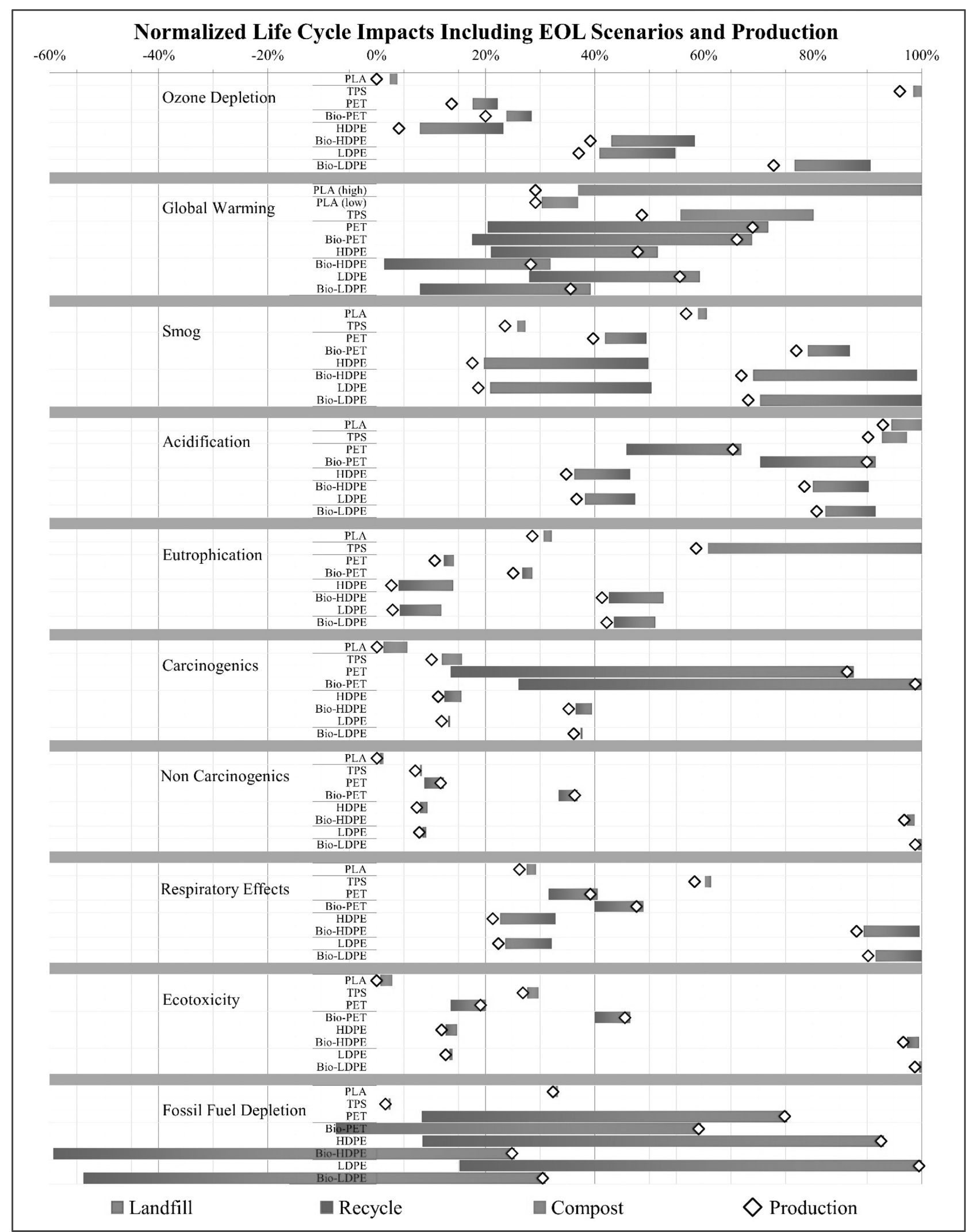

Fig. 2. LCA results using TRACI 2.1 (Bare, 2012) for impact assessment. The graph presents findings for the production and EOL of eight different plastics normalized to the highest relative impact for each category. The production impacts are indicated by a black diamond. EOL scenarios are added to the production diamond and presented as a shaded bar showing the range of two EOL scenarios for each polymer: where $100 \%$ of the polymer is landfilled (red end), $100 \%$ of the polymer is recycled (blue end), or $100 \%$ of the polymer is composted (green end). The range of the EOL model scenarios shows a proportional ratio between the two EOL scenarios for each polymer. The halfway point on each bar is representative of $50 \%$ of the polymer going to the landfill and $50 \%$ going to the alternative. A decrease in impacts for recycling compared to the production impacts is due to offsets from avoiding production of virgin plastics. PLA has high (degradation and no landfill gas capture) and a low (no degradation) emission scenarios in the 'Global warming' category. For all other categories there was no more than a $1 \%$ difference between the two scenarios so only the impacts for low degradation 
diesel fuel per day. The composting inventory developed to model Garick's composting operations was created by combining several unit processes including: $5.1 \mathrm{~kg}$ tap water, $0.0050 \mathrm{~L}$ diesel for powering heavy equipment to process and turn the organic wastes, and $0.18 \mathrm{MJ}$ of heavy equipment use for one kilogram of organics processed (processes given Table S1) (Frischknecht et al., 2005; Weidema et al., 2013). The compost inventories were limited to the emissions directly related to degradation of the polymers and the operations associated with composting on a per kilogram basis for waste materials entering the compost facility. There were no emissions reductions technologies used in the composting processes. The average of the two inventories was used in the model and any differences were explored through the sensitivity analysis.

The two PLA landfill model scenarios distinguished between degradation rates. The high emissions scenario is based on PLA which emits methane as it breaks down in the landfill, 37\% degradation over 100 years, and a total methane generation potential of $174 \mathrm{~N}-1 / \mathrm{kg}$ of PLA, while the low emission scenario is based on PLA which does not degrade under landfill conditions (Kolstad et al., 2012). The methane generated in the high emissions scenario was modeled as an environmental flow rather than estimating a gas capture efficiency and combustion. This was done in order to provide a high-end bounding scenario for landfilling. Both landfill scenarios were created by modifying ecoinvent unit processes for PET landfill disposal by eliminating outliers when compared to PE and cardboard landfill processes as summarized in Table S4. The results for the two PLA landfill model scenarios are presented separately and the differences are discussed.

TPS landfilling was modeled using a proxy process for packaging cardboard disposal from ecoinvent which includes landfill gas capture and flaring (Table S1). There were no EOL inventories available for TPS; according to the available literature, TPS and cardboard have similar material properties and carbon content, which is why it was chosen as a proxy (Shen et al., 2009; Hermann et al., 2011). All of the landfilling scenarios were modeled to evaluate any waste-specific emissions to air and water but excluded ecoinvent's long-term emissions associated with "base lining failure," which allocates the effect of ground water emissions, on a per unit mass basis, from a landfill after the protective lining used to contain wastes has completely failed (Frischknecht et al., 2005; Weidema et al., 2013).

\subsection{Impact assessment}

Using the LCI data described above, the midpoint life cycle impact assessment factors (Tables S5-S7) were calculated using TRACI v2.1 (Tool for the Reduction and Assessment of Chemical and Other Environmental Impacts) (Bare, 2012). TRACI calculates impacts based on the inventories for global warming, eutrophication, ecotoxicity, acidification, ozone depletion, smog formation, carcinogens, non-carcinogens, respiratory effects, and fossil fuel depletion.

A sensitivity analysis was conducted to determine how the variables and assumptions within the study affect the overall results of the LCA and which life cycle phases may yield the greatest returns when looking for system improvement. The sensitivity analysis was conducted using the minimum and maximum values for the multiple process scenarios (e.g. bio-ethylene production, composting process, and MRF type), transportation, and different approaches for recycling allocation. The results, presented in Table S9, are reported in terms of percent change from the baseline model results for the LCA.

\section{Results and discussion}

\subsection{Production impacts}

Fig. 2 illustrates the differences for the life-cycle impacts of polymer production as well as the impacts for the different EOL model scenarios. The production impacts for the bio-ethylene plastics (i.e. Bio-PET, Bio-HDPE, and Bio-LDPE) manufactured using sugar cane grown in Brazil are greater for all the impact categories except for global warming and fossil fuel depletion. The use of agricultural feedstocks such as sugar cane to produce chemica feedstocks (i.e. ethylene) for plastic production requires processes like farming, distillation, and dehydration. Bio-ethylene production introduces different production processes with the most significant impacts resulting from distillation and farming. The process for distillation of ethanol from sugar contributes significantly to ozone depletion, smog, acidification, carcinogens, and respiratory effects. The process for sugar cane farming contributes significantly to ozone depletion, acidification, eutrophication, carcinogens, non-carcinogens, and ecotoxicity. The processes of ethylene dehydration from ethanol, phosphorus based fertilizers, and ocean freighter transportation also contributed to the differences between fossil plastics and the bio-ethylene based alternatives.

PLA and TPS, which are both manufactured using corn, have greater production impacts to the categories of acidification and eutrophication than any of the fossil-based plastics. These impacts are the result of phosphorous, nitrogen, and sulfur which are used in fertilizers for the agricultural processes (e.g. diammonium phosphate, urea, and ammonium nitrate) as well as effluent wastes generated in starch production. TPS has additional nitrogen impacts from natural gas based plasticizers which contributed to acidification. The benefits of using a biogenic carbon source can be seen in the global warming category for production values of the biopolymers, particularly PLA, Bio-HDPE, and Bio-LDPE.

\subsection{EOL impacts}

Global warming impacts vary significantly based on EOL scenario and polymer degradation under landfill conditions. TPS and the high degradation scenario for PLA, which were both modeled to degrade in landfill (Kolstad et al., 2012; Hermann et al., 2011; Krause and Townsend, 2016), emit methane which causes higher global warming impacts than the composting alternative. Methane can be captured from landfills at various rates and flared or burned for energy recovery (Spokas et al., 2006). The emissions from TPS and PLA (high) degradation in landfill cause increased global warming impacts than the alternative composting processes.

The TPS landfill scenario was modeled using a 'packaging cardboard' process, an assumption which was based on material characteristics described in the literature but introduces some parameter uncertainty (Shen et al., 2009; Hermann et al., 2011). The scenario includes landfill gas capture and combustion resulting in $1.18 \mathrm{e}-2 \mathrm{~kg}$ of $\mathrm{CO}_{2}, 2.30 \mathrm{e}-5 \mathrm{~kg}$ of $\mathrm{CH}_{4}$, and $7.57 \mathrm{e}-6 \mathrm{~kg}$ of $\mathrm{CO}$ per kilogram of TPS (Frischknecht et al., 2005). Because there was more specific data regarding degradation of PLA and the results of previous studies were divergent (Kolstad et al., 2012; Krause and Townsend, 2016), bounding scenarios were used to assess reason-

of PLA were graphed. All values for net life-cycle impacts are included in Table S8. The results here represent the average for the compost inventories, material recovery facilities (MRF) inventories, and bio-ethylene production inventories for all relevant model scenarios. These influence of these process scenarios on the results were evaluated in the sensitivity analysis (Table S9). (For interpretation of the references to colour in this figure legend, the reader is referred to the web version of this article.) 
able high and low values for landfill emissions. The high PLA landfill scenario was based on the amorphous PLA degradation rates from Kolstad et al. which falls between the values reported by Krause and Townsend for semicrystalline PLA (Kolstad et al., 2012; Krause and Townsend, 2016). The high degradation scenario included methane generation and did not include any conversion to $\mathrm{CO}_{2}$ via combustion, providing an upper bound for possible impacts for PLA in landfills. Both previous studies on degradation rates found that semicrystalline PLA may not break down under certain landfill conditions and, in this case, landfilling does not incur any emissions from the breakdown of the PLA (Kolstad et al., 2012; Krause and Townsend, 2016). No degradation was assumed for the low PLA scenario. The results for the high emissions PLA represents methane generation with no gas capture so as to present a value for an upper bound for landfill scenarios. The low emissions PLA was modeled with no degradation to represent full sequestration of the biogenic material, producing a lower bound. The production of methane proves to be dominant in the global warming results for PLA which is present in the high degradation landfill scenario.

Fig. 3 shows the process contribution to each impact category for EOL. For PLA and TPS the most notable EOL impacts result from the degradation of the materials themselves as well as the equipment and diesel fuel used at landfills and compost facilities. Composting PLA and TPS results in higher impacts than landfilling in seven categories: smog, acidification, carcinogenics, non-carcinogenics, respiratory effects, ecotoxicity, and fossil fuel depletion. The impacts that are higher for composting result from the use of diesel fuel for heavy machinery and additional water use associated with the composting process. Similar to the recyclable materials, PLA and TPS have contributions to ozone depletion and respiratory effects resulting from waste collection, ground transportation, and intermediate handling. In the case of PLA and TPS these processes are an even larger proportion of the total EOL impacts including $46 \%$ of the ozone depletion impacts for composting of TPS and PLA, 71\% of the global warming impacts for the low emission landfilling scenario for PLA, 68\% of smog impacts for the low emission landfilling scenario for PLA, and $100 \%$ of the fossil fuel depletion impacts for landfilling of PLA and TPS. The large difference between the global warming impacts for PLA in the landfill scenarios is due entirely to the $\mathrm{CH}_{4}$, which contributes $98 \%$ of the global warming emissions in the high emission scenario. For composting PLA, $89 \%$ of the global warming impacts are from the composting process and are largely due to the biogenic emissions from the PLA degrading. Likewise, the composting and landfilling processes for TPS equate to $89 \%$ and $97 \%$ respectively for global warming impacts of TPS EOL scenarios. The landfill emissions for the high emission PLA scenario and TPS are worse than for composting. Because degradation of these materials is inherent to the composting process, any improvements aimed at minimizing global warming impacts for composting should focus on reducing the contributions from transportation and handling. Transportation and handling contribute to the global warming emissions for the composting scenario for PLA with 10.5\% resulting from the waste collection, transfer station processes, and transportation while $5.5 \%$ are due to operations of the compost facility. For TPS those values are $11.5 \%$ and $8.5 \%$ respectively. These data are presented as normalized values relative to the largest contribution for each category but do not represent the magnitude of the impacts across the categories. All of the total impacts are provided in Table S6 for reference.

Recycling has major implications for the life-cycle impacts of the traditional plastics and their bio-based counterparts (Fig. 2). In some categories, recycling decreases the impacts associated with production because the benefits from offsetting virgin plastic production are allocated to the materials. This is the case for global warming and fossil fuel depletion for all of the recyclable plastics,

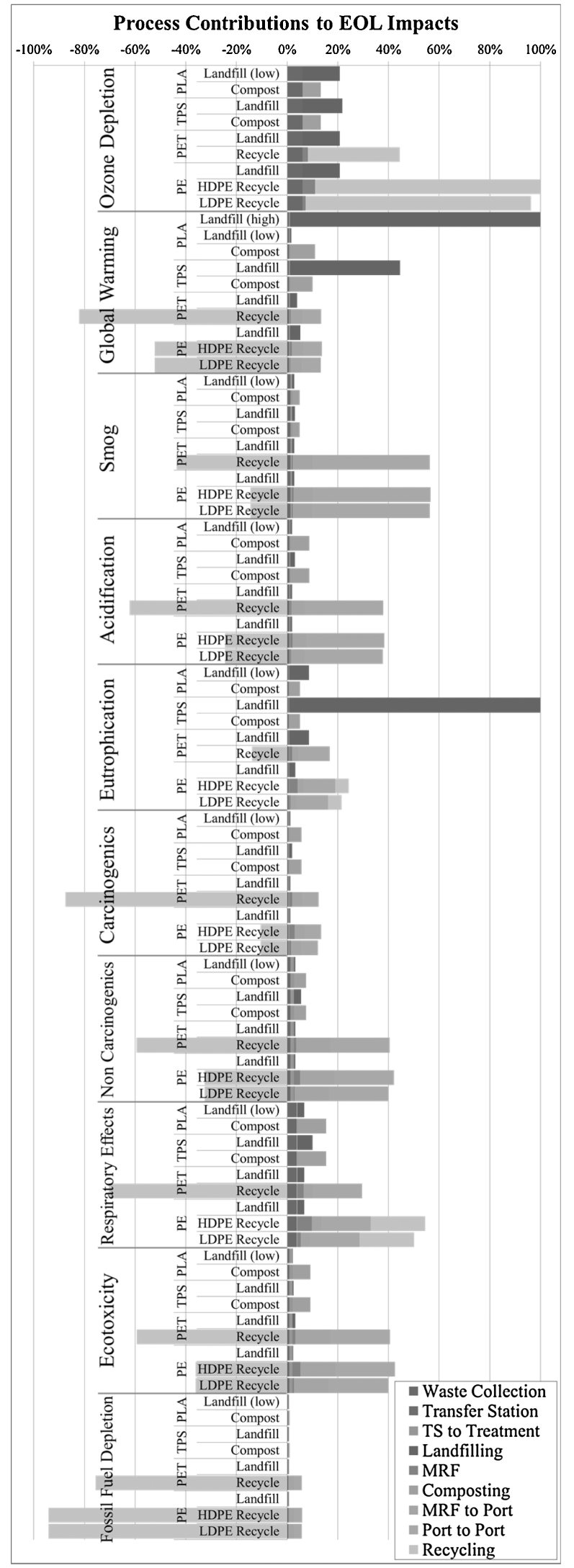

Fig. 3. Process contributions to $\mathrm{EOL}$ impacts. $\mathrm{TS}=$ transfer station, $\mathrm{MRF}=$ material recovery facility, port to port = shipping from Long Beach, CA to Hong Kong, China. Recycling includes energy for recycling and offsets to virgin production. 
as well as carcinogenics for PET and Bio-PET. For ozone depletion and smog, recycling incurs additional impacts beyond those of landfilling due to the transportation of the recyclable plastics from the material recovery facility to the recycling facility in China.

The offsets gained by recycling in the global warming and fossil fuel depletion categories are further accentuated by the use of bio-based ethylene for the production of Bio-PET, Bio-HDPE, and Bio-LDPE. Because the model assumes the recycling of these polymers offsets the production of fossil-based resins, the recycled bio-polymers achieve negative life-cycle impacts in the fossil fuel depletion category by avoiding the use of fossil resources through virgin production of traditional plastics, shown in Fig. 2 . While the initial production processes are important, including EOL demonstrates that waste handling methods are also a critical factor in the environmental performance of plastics.

The most notable impacts result from the offsets of virgin production and energy used during recycling, the equipment and fuel used at landfills, and the freighter shipping for bailed recyclables (Fig. 3). The waste collection, ground transportation, and intermediate handling (i.e. transfer station and MRF) are not major contributors for most of the impact categories; these processes combined for recyclables contribute, at most, to eleven percent (HDPE) of the maximum category impact in the ozone depletion and ten percent (HDPE) of the maximum impact for respiratory effects. International shipping does not need to be inherent to the process of recycling and the shipping incurs significant impacts, particularly for $\operatorname{smog}(47 \%)$, acidification (31\%), non-carcinogenics (24\%), respiratory effects (20\%), and ecotoxicity (17\%). Greater environmental benefits from recycling could be achieved if recyclable materials were not shipped overseas. The results of the sensitivity analysis explore the impacts associated with the loss of useful material during the recycling process. Polymer forming technologies (including the use of plasticizers), production methods, the 'down-cycling' of plastics to lower grade material, and life-spans for specific products were not evaluated in this study but may impact not only production but also the recyclability and recovery rates associated with biopolymers and traditional plastics.

Fig. 4 presents the binary EOL options on a sliding scale from $100 \%$ landfill and $0 \%$ recycling/compost to $0 \%$ landfill and $100 \%$ recycling/compost. This figure is focused on the EOL options available and does not account for upstream impacts, including embedded biogenic carbon. Fig. 4 shows the difference in impacts from landfilling based on the assumptions regarding methane generation for high emissions (A) and low emissions (B) PLA. Fig. 4 also shows a traditionally recyclable plastic, PET (C), and the results for TPS (D), which incurs greater impacts when landfilled due to methane generation from anaerobic degradation like the high emission scenario for PLA. Fig. 4 also shows the current recycling rate of PET in the United States and the potential impact reductions that could be achieved if the recycling rate increased.

The graphs in Fig. 4 enable EOL decision makers to visualize the impacts associated with disposal and quantify their environmental goals. An organization with specific environmental goals could use these results to optimize waste treatment strategy to achieve their objectives. The results suggest that a zero waste to landfill strategy, as has been the approach for some institutions and municipalities, may not achieve the greatest environmental performance in all cases. While the low emissions PLA scenario has lower impacts than composting in seven categories which is borne out in the full life-cycle presented in Fig. 2, the systemic impacts of the entire lifecycle can also be important. If, for example, food waste to landfill could be avoided using PLA cutlery and a single stream composting collection at event venues and food service establishments, the benefits of creating an easily compostable waste stream to avoid methane generation from food waste may outweigh the emissions associated with composting PLA.

\subsection{Sensitivity analysis}

The sensitivity analysis evaluated the significance of the process scenarios, transportation, and recycling allocation methods for the recycling and composting scenarios. For each set of process scenarios (e.g. MRF technology, ethylene inventory, and local transportation) the minimum and maximum results (ethylene process scenarios described in Methods section and SI for the MRF and transportation are in Tables S1 and S2) were tested against the baselines used to model the lifecycle impacts displayed in Fig. 2. This analysis highlights the areas within the assessment that are most critical with regards to data quality and system improvement for improved environmental performance for the processes. The topics emphasized in this discussion are factors which demonstrated higher sensitivity within the model. Table S9 in the SI presents the full results of the sensitivity analysis for all of the polymers and impact categories.

Transportation proved to be the most significant process associated with recycling as and EOL pathway. 'Baled Recyclables Shipping' was represented in the LCA by a long transportation scenario, which is $610 \mathrm{~km}$ ground transport and $11,686 \mathrm{~km}$ ocean freighter transport. The lower boundary represents not sending recyclable plastics to China via international freight but includes $610 \mathrm{~km}$ of interstate ground transportation. The process 'Baled Recyclables Shipping' stood out as the most significant in terms of sensitivity for global warming impacts with shifts in the results as much as $-392 \%$ for Bio-HDPE and -68\% for Bio-LDPE, suggesting a large share of the global warming emissions in the recycling scenarios are driven by international shipping (also shown in Fig. 3). Since the LCA modeled shipping to China based on current real-world operations the sensitivity here demonstrates only potential savings represented by negative values. Local transportation and waste collection only showed major sensitivities in the global warming category for Bio-HDPE, which had very low baseline impacts relative to the other plastics.

The results for PET and HDPE were more sensitive than the other polymers to the MRF technologies used for sorting recyclables because the sorting process is more intensive for these materials compared to LDPE and they have very low baseline impacts for eutrophication, carcinogenics, and ecotoxicity which were the categories which were most impacted. Bio-HDPE showed high sensitivity in the global warming category with a $-53 \%$ shift given the minimum and $+96 \%$ shift given the maximum, while Bio-LDPE showed no change because the sorting processes based on differing MRF technologies do not impact the results as significantly. HDPE and Bio-HDPE also demonstrated the highest sensitivities because they had the lowest baseline impacts for a recycling scenario across most of the categories so the relative significance of the changes to the inventories was greater.

The alternative recycling allocation methods, 'substitutionwith-correction-factor' and 'substitution-with-equal-quality' demonstrate the significance of recycling allocation methods. The 'substitution-with-correction-factor' was used with a correction factor of 0.7 (representing a 30\% loss during EOL processing) and applied to all recyclable polymers. Predictably, this approach results in greater impacts across all categories with particular significance in the global warming and fossil fuel depletion categories for all of the recyclable polymers. PET and Bio-PET also have large increases in the carcinogenics impact category. The 'substitution-with-equal-quality' approach was applied to the recyclable biopolymers which had been modeled using a 'substitution-with-alternative-material' approach based on the assumption that the recycled material would offset the fossil-based 


\section{Assessing Global Warming Impacts for EOL Options}

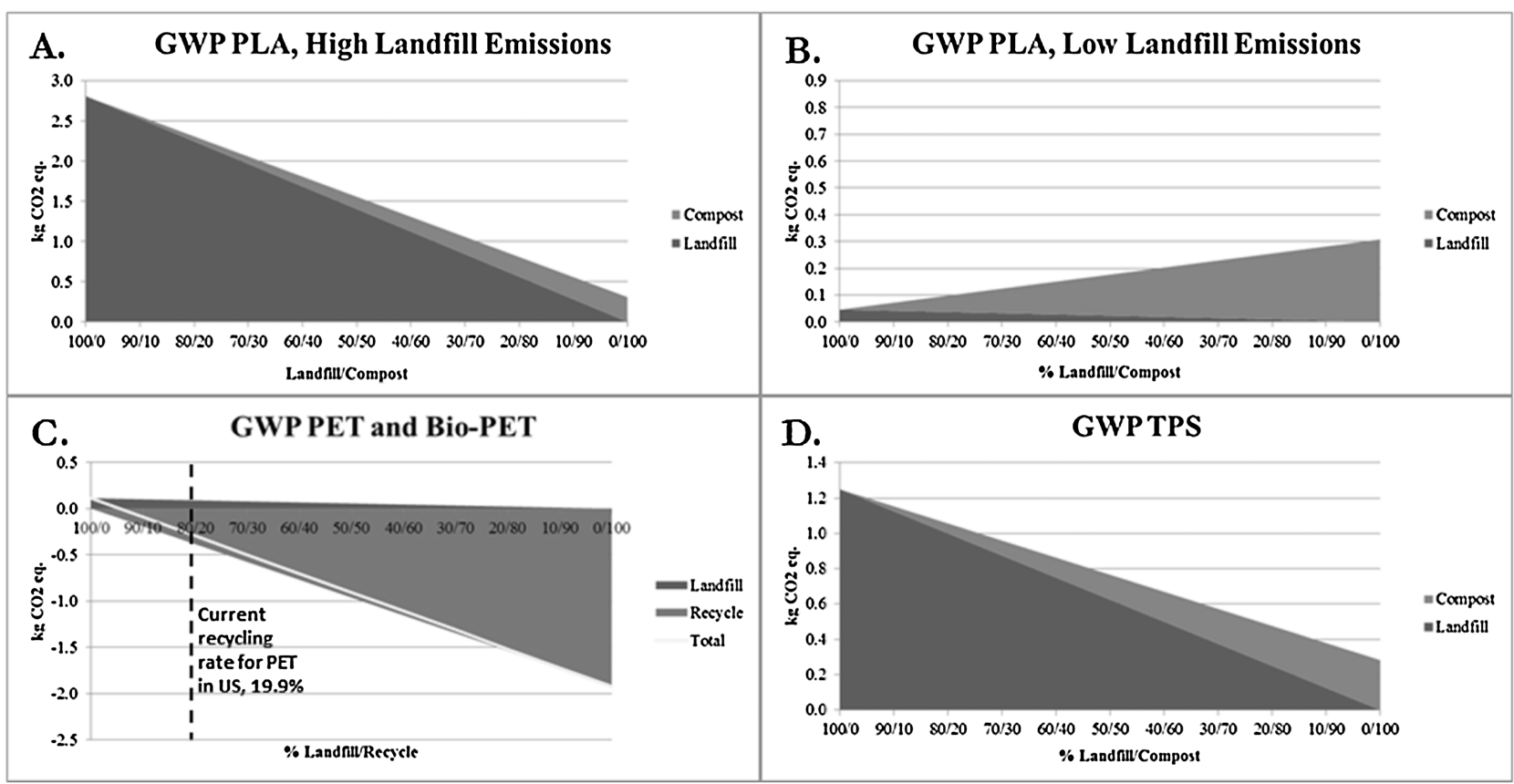

Fig. 4. Global warming impacts for EOL scenarios scaled from $100 \%$ landfilling and $0 \%$ recycling/composting to $0 \%$ landfilling and $100 \%$ recycling/composting for high (A) and low (B) emission scenarios for PLA, PET, and Bio-PET (C), and TPS (D). The current recycling rate for PET is indicated in (C) at 19.9\% (USEPA, 2015). A zero waste to landfill strategy would be represented by reading the values at the far right of the graphs. For the low emission PLA scenario (B) a zero waste to landfill approach would result in greater impacts. Results for all polymers and impact categories can be found in Table S10.

equivalent. This alternative allocation method resulted in tradeoffs which are proportional to the differences in production between the two potential virgin polymers being offset for each biopolymer. For all recyclable biopolymers (Bio-PET, Bio-HDPE, and Bio-LDPE) global warming potential and fossil fuel depletion increase while all other impact categories decrease. The global warming potential for Bio-PET, Bio-HDPE, and Bio-LDPE are 0.81, 0.83, and $1.09 \mathrm{CO}_{2}$ eq. respectively. The fossil fuel depletion is $1.00,1.02$, and $1.68 \mathrm{MJ}$ surplus respectively. The reductions in the other categories fell between $21 \%$ and $91 \%$ across all of the biopolymers.

The ethylene inventories, which were developed by Tabone et al. (2010) and revised for this study to help address the uncertainty of the process did not vary widely. They were similar with regards to global warming potential and create at most a $6 \%$ shift in the ecotoxicity category for Bio-HDPE and Bio-LDPE. For all other categories the largest difference was a $3 \%$ change. The transportation associated with bio-ethylene shipping from Brazil was very similar to the reductions associated to the 'Baled Recyclables Shipping' to China described above. Again, the most significant difference occurred in the global warming category.

\subsection{Discussion}

This research builds on previous LCAs of biopolymers by examining not only the production of biopolymers, but it also evaluates EOL pathways based on disposal options available to consumers. Similar to Madival et al. (2009), one the few previous studies that evaluated multiple EOL pathways for biopolymers (Hottle et al., 2013), this LCA found that recycling results in significant life cycle impact reductions. Additionally, both studies found that transportation can significantly contribute to a number of impacts in multiple life cycle phases (Madival et al., 2009). The LCA presented here expands on the range of biopolymers evaluated in an LCA by including PLA, TPS, and bio-based equivalents for PET, HDPE, and
LDPE. The use of composting scenarios, uncommon in past LCAs (Hottle et al., 2013), was accomplished using original and previously published process inventories as well as recently developed inventories for degradation. The landfill scenarios for PLA highlight the divergence between the studies by Kolstad et al. (2012) and Krause and Townsend (2016) regarding degradation rates. This LCA defines upper and lower bounds for emissions associated with landfilling PLA.

Future work can be done to assess the consequential implications of forming technologies for biopolymers and the shift towards large scale implementation of composting including the potential to increase food waste diversion from landfills. Additionally, there are many factors that contribute to the carbon emissions related to organic degradation for both landfilling and composting operations with significant uncertainty regarding utilized technologies, degradation rates, landfill temperature, methane generation, landfill gas capture efficiency, landfill gas use, and modeling approaches (Krause and Townsend, 2016; Levis and Barlaz, 2011; Hottle et al., 2016; Heijungs and Guinée, 2007).

\section{Conclusion}

This study demonstrates that production and EOL of biopolymers and fossil-based plastics must be accounted for when evaluating the life cycle environmental impacts of plastics. Environmental performance is not limited to purchasing decisions (i.e. production of plastics), and availability of disposal options can significantly influence the overall life cycle impacts. Despite impacts related to shipping or demand for recyclable material in the current market, recycling proves to have major benefits due to avoidance of creating new plastics from virgin resources. The benefits of recycling could extend to biopolymers if they can be recycled in existing waste streams. TPS and PLA may find additional life cycle benefits if they can scale adequately to warrant recycling. The benefits of 
fossil based plastics are most notable in the global warming and fossil fuel depletion impact categories. Decision makers along the supply chain looking to improve environmental performance for packaging and disposable goods can use these results to better understand purchasing and waste handling in the context of realworld waste handling options. For example; zero waste, or landfill avoidance, waste management strategies do not always result in lower environmental impacts.

\section{Acknowledgments}

This work was supported by the National Science Foundation Award No. CBET 1066658/1246547/1553126 -Evaluating Sustainable Disposal Options for Compostable Biopolymers. Any opinions, findings and conclusions or recommendations expressed in this material are those of the authors and do not necessarily reflect the views of NSF. Special thanks to the research support provided by Diana Meeks and Marisol Luna Agüero. Partial support of this work was provided by the Environmental Research and Education Foundation, through a scholarship for Troy Hottle.

\section{Appendix A. Supplementary data}

Supplementary data associated with this article can be found, in the online version, at http://dx.doi.org/10.1016/j.resconrec.2017. 03.002.

\section{References}

Álvarez-Chávez, C.R., Edwards, S., Moure-Eraso, R., Geiser, K., 2012. Sustainability of bio-based plastics: general comparative analysis and recommendations for improvement. J. Clean. Prod. 23 (1), 47-56.

ASTM, 2003. ASTM D6868;1 - 03 Standard Specification for Biodegradable Plastics Used as Coatings on Paper and Other Compostable Substrates. ASTM International, West Conshohocken, PA.

ASTM, 2004. ASTM D6400;1 - 04 Standard Specification for Compostable Plastics. ASTM International, West Conshohocken, PA.

Bare, J., 2012. Tool for the Reduction and Assessment of Chemical and Other Environmental Impacts (TRACI)(Version 2.1)[Software], Cincinnati, OH.

Björklund, A., Finnveden, G., 2005. Recycling revisited-life cycle comparisons of global warming impact and total energy use of waste management strategies. Resour. Conserv. Recycl. 44 (4), 309-317.

Brehmer, B., Sanders, J., 2009. Assessing the current Brazilian sugarcane industry and directing developments for maximum fossil fuel mitigation for the international petrochemical market. Biofuels Bioprod. Biorefin. 3 (3), 347-360.

Cedar Grove Compostabilty Testing. http://cedar-grove.com/compostable/ compostability-testing/ (February 2014).

Coca-Cola Coca-Cola GRI Report; The Coca-Cola Company: 7 October 2012, 2012.

European Bioplastics, 2014. Bioplastics Facts and Figures.

Franklin Associates Revised Final Report, 2011. Franklin Associates Revised Final Report: Cradle-To-Gate Life Cycle Inventory of Nine Plastic Resins and Four Polyurethane Precursors; Prairie Village, Kansas, 8/16/2011.

Frischknecht, R., Jungbluth, N., Althaus, H.J., Doka, G., Dones, R., Heck, T., Hellweg, S., Hischier, R., Nemecek, T., Rebitzer, G., Spielmann, M., 2005. The ecoinvent database: overview and methodological framework. Int. J. Life Cycle Assessment 10, 3-9.

Gómez, E.F., Michel Jr, C., 2013. Biodegradability of conventional and bio-based plastics and natural fiber composites during composting, anaerobic digestion and long-term soil incubation. Polym. Degrad. Stab. 98 (12), 2583-2591.

Geyer, R., Kuczenski, B., Zink, T., Henderson, A., 2016. Common misconceptions about recycling. J. Ind. Ecol. 20 (5), 1010-1017.

Ghorpade, V.M., Gennadios, A., Hanna, M.A., 2001. Laboratory composting of extruded poly (lactic acid) sheets. Bioresour. Technol. 76 (1), 57-61.

Gironi, F., Piemonte, V., 2011. Life cycle assessment of polylactic acid and polyethylene terephthalate bottles for drinking water. Environ. Progress Sustain. Energy 30 (3), 459-468.

Hartmann, M.H., 1998. Biopolymers from Renewable Resources. Springer, New York, p xviii, 417 p.

Heijungs, R., Guinée, J.B., 2007. Allocation and 'what-if' scenarios in life cycle assessment of waste management systems. Waste Manage. 27 (8), 997-1005.

Hermann, B.G., Debeer, L., De Wilde, B., Blok, K., Patel, M.K., 2011. To compost or not to compost: carbon and energy footprints of biodegradable materials' waste treatment. Polym. Degrad. Stab. 96 (6), 1159-1171.

Hopewell, J., Dvorak, R., Kosior, E., 2009. Plastics recycling: challenges and opportunities. Philos. Trans. R. Soc. Lond. B: Biol. Sci. 364 (1526), 2115-2126.

Hottle, T.A., Bilec, M.M., Landis, A.E., 2013. Sustainability assessments of bio-based polymers. Polym. Degrad. Stab. 98 (9), 1898-1907.
Hottle, T.A., Bilec, M.M., Brown, N.R. Landis, A.E., 2015. Toward zero waste: composting and recycling for sustainable venue based events. Waste Manage. 38, 86-94.

Hottle, T.A., Agüero, M.L., Bilec, M.M., Landis, A.E., 2016. Alkaline amendment for the enhancement of compost degradation for polylactic acid biopolymer products. Compos. Sci. Util. 24 (3), 159-173.

ISO Environmental management, 2006. ISO Environmental management-Life cycle assessment-Principles and framework; ISO 14044:2006. International Organization for Standardization, Switzerland.

ISO Environmental management, 2006. ISO Environmental management-Life cycle assessment-Principles and framework; ISO 14040:2006. International Organization for Standardization, Switzerland.

Jamshidian, M., Tehrany, E.A., Imran, M., Jacquot, M., Desobry, S., 2010. Poly-lactic acid: production, applications, nanocomposites, and release studies. Compr. Rev. Food Sci. Food Saf. 9 (5), 552-571.

Kijchavengkul, T., Auras, R., 2008. Compostability of polymers. Polym. Int. 57 (6), 793-804.

Koller, M., Sandholzer, D., Salerno, A., Braunegg, G., Narodoslawsky, M., 2013. Biopolymer from industrial residues: life cycle assessment of poly (hydroxyalkanoates) from whey. Resour. Conserv. Recycl. 73, 64-71.

Kolstad, J.J., Vink, E.T.H., De Wilde, B., Debeer, L., 2012. Assessment of anaerobic degradation of Ingeo ${ }^{\mathrm{TM}}$ polylactides under accelerated landfill conditions. Polym. Degrad. Stab. 97 (7), 1131-1141.

Krause, M.J., Townsend, T.G., 2016. Life-cycle assumptions of landfilled polylactic acid underpredict methane generation. environmental science. Technol. Lett. 3 (4), 166-169.

Kruger, M., Kauertz, B., Detzel, A., 2009. Life Cycle Assessment of Food Packaging Made of Ingeo Biopolymer and (r) PET IFEU Report, Heidelberg.

Landis, A.E., Miller, S.A., Theis, T.L., 2007. Life cycle of the corn-soybean agroecosystem for biobased production. Environ. Sci. Technol. 41 (4), 1457-1464.

Levis, J.W., Barlaz, M.A., 2011. What is the most environmentally beneficial way to treat commercial food waste? Environ. Sci. Technol. 45 (17), 7438-7444.

Madival, S., Auras, R., Singh, S.P., Narayan, R., 2009. Assessment of the environmental profile of PLA, PET and PS clamshell containers using LCA methodology. J. Clean. Prod. 17 (13), 1183-1194.

Meeks, D., Hottle, T., Bilec, M.M., Landis, A.E., 2015. Compostable biopolymer use in the real world: stakeholder interviews to better understand the motivations and realities of use and disposal in the US. Resour. Conserv. Recycl. 105, 134-142.

Miller, S.A., Landis, A.E., Theis, T.L., 2007. Feature environmental trade-offs of biobased production. Environ. Sci. Technol. 41 (15), 5176-5182.

Mohee, R., Unmar, G., 2007. Determining biodegradability of plastic materials under controlled and natural composting environments. Waste Manage. 27 (11), 1486-1493.

Morschbacker, A., 2009. Bio-ethanol based ethylene. Polym. Rev. 49 (2), 79-84.

NREL, 2012. U.S. Life Cycle Inventory Database, 1.6 ed. National Renewable Energy Laboratory, pp. 2012.

NatureWorks LLC Ingeo resin product guide. http://www.natureworksllc.com/ /media/Technical_Resources/onepagers/ingeo-resin-grades-brochure_pdf.

Piemonte, V., 2011. Bioplastic wastes the best final disposition for energy saving. J Polym. Environ. 19 (4), 988-994.

Plastics Technology Coca-Cola Debuts First 100\% Biobased PET Bottle. http://www. ptonline.com/articles/coca-cola-debuts-first-100-biobased-pet-bottle(2) (21 February 2017)

Pressley, P.N., Levis, J.W., Damgaard, A., Barlaz, M.A., DeCarolis, J.F., 2015. Analysis of material recovery facilities for use in life-cycle assessment. Waste Manage. 35 (0), 307-317.

Ren, X., 2003. Biodegradable plastics: a solution or a challenge? J. Clean. Prod. 11 (1), 27-40.

Rossi, V., Cleeve-Edwards, N., Lundquist, L., Schenker, U., Dubois, C., Humbert, S. Jolliet, O., 2014. Life cycle assessment of end-of-life options for two biodegradable packaging materials: sound application of the european waste hierarchy. J. Clean. Prod.

Shen, L., Patel, M.K., 2008. Life cycle assessment of polysaccharide materials: a review. J. Polym. Environ. 16 (2), 154-167.

Shen, L., Haufe, J., Patel, M.K., 2009. Product Overview and Market Projection of Emerging Bio-based Plastics PRO-BIP 2009. Utrecht University.

Shen, L., Worrell, E., Patel, M., 2010. Present and future development in plastics from biomass. Biofuels Bioprod. Biorefin. 4 (1), 25-40.

Song, J.H., Murphy, R.J., Narayan, R., Davies, G.B.H., 2009. Biodegradable and compostable alternatives to conventional plastics. Phil. Trans. R. Soc. B : Biol. Sci. 364 (1526), 2127-2139.

Soroudi, A., Jakubowicz, I., 2013. Recycling of bioplastics, their blends and biocomposites: a review. Eur. Polym. J. 49 (10), 2839-2858.

Spokas, K., Bogner, J., Chanton, J.P., Morcet, M., Aran, C., Graff, C., Golvan, Y.M.-L., Hebe, I., 2006. Methane mass balance at three landfill sites: what is the efficiency of capture by gas collection systems? Waste Manage. 26 (5), 516-525.

Tabone, M.D., Cregg, J.J., Beckman, E.J., Landis, A.E., 2010. Sustainability metrics life cycle assessment and green design in polymers. Environ. Sci. Technol. 44 (21), 8264-8269.

USEPA, 2015. Advancing Sustainable Materials Management: Facts and Figs. 2013: Assessing Trends in Material Generation. Recycling and Disposal in the United States; USEPA. 
van der Harst, E., Potting, J., Kroeze, C., 2016. Comparison of different methods to include recycling in LCAs of aluminium cans and disposable polystyrene cups. Waste Manage. 48, 565-583.

Vink, E.T.H., Davies, S., 2015. Life cycle inventory and impact assessment data for 2014 Ingeo $^{\mathrm{TM}}$ polylactide production. Ind. Biotechnol. 11 (3), 167-180.

Vink, E.T.H., Davies, S., Kolstad, J.J., 2010a. The eco-profile for current Ingeo polylactide production. Ind. Biotechnol. 6 (4), 212-224.

Vink, E.T.H., Davies, S., Kolstad, J.J., 2010b. ORIGINAL RESEARCH. The eco-profile for current Ingeo ${ }^{\circledast}$ polylactide production. Ind. Biotechnol. 6 (4), 212-224.
Weidema, B.P., Bauer, C., Hischier, R., Mutel, C., Nemecek, T., Reinhard, J., Vadenbo, C.O., Wernet, G., 2013. The Ecoinvent Database: Overview and Methodology, Data Quality Guideline for the Ecoinvent Database Version 3.Weiss, M., Haufe, J., Carus, M., Brandão, M., Bringezu, S., Hermann, B., Patel, M.K., 2012. A review of the environmental impacts of biobased materials. J. Ind. Ecol. 16, S169-S181. Yates, M.R., Barlow, C.Y., 2013. Life cycle assessments of biodegradable, commercial biopolymers-a critical review. Resour. Conserv. Recycl. 78, 54-66. 